\title{
Overcoming Barriers in Higher Education Mobility between Latin America, Canada and Asia: A Scoping Review
}

\author{
Arooba Ahmed ${ }^{1}$, Jia Jun Joel Wen ${ }^{2}$, Maribel Flórez ${ }^{3}$, Pedro Iacobelli ${ }^{4} \&$ Lilian Ferrer $^{5}$ \\ ${ }^{1}$ Columbia College, Columbia University in the City of New York, New York, United States \\ ${ }^{2}$ School of General Studies, Columbia University in the City of New York, New York, United States \\ ${ }^{3}$ Director of Global Education at the Office of the Vice President for International Affairs, Pontificia Universidad \\ Católica de Chile, Santiago, Chile \\ ${ }^{4}$ Director of the Centre for Asian Studies, Pontificia Universidad Católica de Chile, Santiago, Chile \\ ${ }^{5}$ Vice President for International Affairs, Pontificia Universidad Católica de Chile, Santiago, Chile \\ Correspondence: Maribel Flórez, Office of the Vice President for International Affairs, Pontificia Universidad \\ Católica, Santiago, Chile.
}

Received: September 25, 2020

Accepted: July 8, 2021

Online Published: July 9, 2021

doi:10.5430/ijhe.v11n1p43

URL: https://doi.org/10.5430/ijhe.v11n1p43

\begin{abstract}
Latin America and Asia have been tied for hundreds of years through a transcontinental trade network, which has culminated in their current economic interdependence. This interdependence necessitates cooperation, which can be bolstered through cultural understanding between the two continents. International student mobility is one way to foster intercultural relations, which are currently quite low between these regions. Canada has faced a similar struggle as Latin America to attract students in the Americas when faced with competition from US universities, but has had some successes which Latin American countries could learn from. This study therefore completes a scoping review of the literature to categorize barriers and enablers to academic mobility between higher education institutions (HEIs) in Asia, Canada, and Latin America and synthesizes relevant suggestions. An integrative literature search of qualitative and quantitative studies was conducted using six different databases. After considering inclusion and exclusion criteria, 33 studies were selected and analyzed. The results were categorized into six themes: Cultural, Academic and Professional, Linguistic, Economic, Program Structure, and Political Climate. Each theme included factors which enabled or hindered student mobility between Asia and the Americas. The findings highlight the need for Latinamerican HEIs to emphasize relevant initiatives and qualities that go beyond rankings, boost the use of English among academics and staff, actively reach out to Asian partners, and collaborate to develop credit transfer policies compatible with Asian institutions. These considerations could be all the more timely considering students are currently more open to virtual international opportunities in the midst of the COVID-19 pandemic, generating possibilities of greater collaboration between these regions of the world.
\end{abstract}

Keywords: Latin America, Asia, Canada, higher education, international student mobility, study abroad

\section{Introduction}

\subsection{Latin American and Asian Ties}

Latin American and Asian ties have existed for centuries. Goods from both regions were highly valued during the 16th to 19th centuries and led to the development of critical trade routes (Winston, 2016). Particularly in the 17th century, Spanish control over silver mines in Latin America fostered a trans-Pacific link that drove trade between Latin America and Asia in the South China Sea (Spate, 1979; Montt \& Rehner, 2020).

Trade between the two regions has evolved since then. According to the Asian Infrastructure Investment Bank (AIIB), both regions' total trade amounted to USD 62 billion in 1995. Since then, total trade between Asia and Latin America has been on the rise, increasing seven-fold to USD 465.0 billion in 2016 (Asian Infrastructure Investment Bank \& The Economist Intelligence Unit, 2019). This increase in trade has created unprecedented ties between the two regions.

Latin American countries conduct strong trade with many Asian countries. For example, three out of the five main Chilean customer countries are from Asia, with China being Chile's main trading partner (Santander Trade, 2020). China was also Brazil's top trading partner (World Integrated Trade Solution [WITS], 2020a) and one of Mexico's top 
five trading partners (WITS, 2020b) in imports and exports in 2018. Asian companies have also increased investment in Latin America. For example, Asian companies such as Honda, Viettel, and Hansoll Textile have operations based in Latin American countries (BIZ Latin Hub, 2020). These ties make it crucial for both regions to obtain an understanding of each other's cultures to ensure continuity of good international relations.

Enhanced student mobility between these two regions may provide a platform for closer ties by increasing cultural exposure. For this study, international mobility is defined as border-crossing for the purpose of embarking into study in the country of destination (Teichler, 2017). Although there Asian international students in Organization for Economic Co-operation and Development (OECD) countries have increased (OECD, 2019; The Asian Development Bank Institute, OECD and International Labor Organization, 2014), there are currently very few Asian students in Latin America. China and India respectively, sent approximately 900,000 and 300,000 students abroad in 2019, but less than one percent of these students chose Latin America as a destination for their studies (UNESCO Institute of Statistics, 2020). Although Latin America and the Caribbean have seen an increasing number of students in higher education, this region remains one of the least popular destinations for international students. Only 3.5 percent of the five million mobilized international students every year choose it as a location for their studies. As such, Latin American and Caribbean institutes fail to attract students from other regions beyond their own (UNESCO International Institute for Higher Education in Latin America and the Caribbean, 2019). In Latin America, for example, the percent of international students from Asia is the second-lowest out of all the other continents, at 1.3 percent (Boston College Center for International Higher Education, 2016), surpassing only Africa. In 2007, Latin America and the Caribbean represented six percent of mobile students worldwide, totaling just 168,231. For Mexico, Colombia, Peru, Venezuela, and Ecuador, the top destinations were the USA, Spain, UK, France, Spain, and Chile. Asian countries are not among their top choices (Casallas, 2010).

\subsection{Rationale}

Prior research on drivers of international mobility in tertiary education suggests that the lack of mobility between Latin America and Asia may be due to the predominance of vertical mobility worldwide. Students often aim to achieve higher competency than what they could expect to reach through study at home through mobility (Teichler, 2017). Similarly, students are motivated to study internationally by the prospect of building skills that amplify their employment opportunities (Farrugia, 2017). Horizontally mobile students, on the other hand, are those that seek to contrast what they have experienced at home in a variety of aspects that may include the teaching and learning process, the substance of knowledge taught, or the social and cultural environment (Teichler, 2017). We were interested in learning about how these drivers contribute to or prevent international student mobility between these two continents.

Studies on student mobility between Asia and Latin America are overshadowed by a plethora of studies that include more popular destinations for Asian students, such as the United States or the United Kingdom. In this context, Canada is particularly relevant due to its more isolated geography and possession of an official language other than English, which pose obstructions to higher education mobility shared by Latin American institutions (Friedman and Mauldin Economics, 2017). Therefore, this literature review seeks to better understand the mobility between the Americas and Asia, excluding the United States, due to the U.S.'s current status as one of the world's leading educational destinations (Tobenkin, 2020). This work separates the studies which focus solely on transcontinental mobility between Asia and the U.S. from those that involve other American countries to consolidate the reasoning as to why Latin American institutions have been unable to connect with their Asian counterparts.

Pontificia Universidad Católica de Chile (UC Chile) is one of the six Catholic Universities in the Chilean university system and one of the two Pontifical Universities in Chile. Chile ranks at the top in the region (Boston College Center for International Higher Education, 2016) in receiving international flows and in sending students abroad. UC Chile also leads all other Chilean universities in the proportion of its students who go abroad and in the proportion of its student body who come from abroad (De Wit, Jaramillo, Gacel-Ávila, \& Knight, 2005). UC Chile finds great value in international students and in making connections with other higher education institutions. For example, in 2019, the university received 1,451 students from 256 institutions in 45 different countries and distributed 835 students among 126 institutions in 30 countries (Pontificia Universidad Católica de Chile, 2020). The university has now decided it needs an internationalization policy to strengthen and diversify the internationalization of academic and enrichment programs and research initiatives through a close relationship with universities and world-class research centers around the globe (Boston College Center for International Higher Education, 2016). Considering Chile's role in economic cooperation with Asian countries and the current low educational cooperation with Asian higher education institutions (HEIs), this literature review should help identify specific mechanisms to improve its programs by clearly examining the barriers and enablers to academic mobility between these two regions. 
In addition, the COVID-19 pandemic has created a need for social distancing and limited physical contact. Many countries have placed travel restrictions to formally halt contact. This has disrupted most international student mobility, higher education, and research (Redden, 2020; Grove, 2020). Universities have instead turned to remote education as an alternative, but there are many challenges that come with adaptation. In the current context, it is more important than ever to learn from other institutions, especially Asian institutions, on how to handle the transition to virtual opportunities. In China, for example, Zhejiang University (ZJU) moved more than 5000 courses online in two weeks (World Bank, 2020). With the transition to virtual higher education, this is a great opportunity to bridge the geographic gap between Asia and Latin America and utilize the findings from these studies to create an exchange program. Virtual global exchange programs might be attractive since students are still looking for extracurricular opportunities and attempting to boost their resume.

\section{Methodology}

We conducted a search of literature published between 2000 and 2020 in six electronic databases: Scopus, EBSCO, JSTOR, ERIC, ProQuest, and Scielo. Scopus was chosen based on the fact that ranking systems such as QS and Times Higher Education prioritize Scopus publications. Scielo was chosen because the database prioritizes literature published in Latin American countries. The others were chosen for their prominence in the Education and Social Sciences fields.

Our search terms were grouped into three categories. The first focused on geography of the Americas. We chose to include names of Spanish speaking, Latin American countries who were the regional leaders in education (Holm-Nielsen, Thorn, Brunner, \& Balán, 2005; U.S. News \& World Report, 2020) and involved in economic trade with Asia. Our second category was representative of Asian countries who were also leaders in higher education output (UNESCO Institute for Statistics, 2014) and had strong ties to Latin American countries (Estevadeordal, 2018; Wilson Center, 2014). The final category framed the internationalization in an educational context and broadened the mobility beyond physical mobility (to include virtual mobility). We decided to keep the term "higher education" as a constant in all our searches to restrict our search results to HEIs.

Search terms combined one term from each of the first two categories with all the possibilities in the third category that were separated by the Boolean operator "OR." Search terms across the three categories were combined using the Boolean operator "AND." The first three combinations of searches did not utilize parentheses or quotation marks around the categories and individual search terms, but to refine our searches we added them to the latter three combinations.

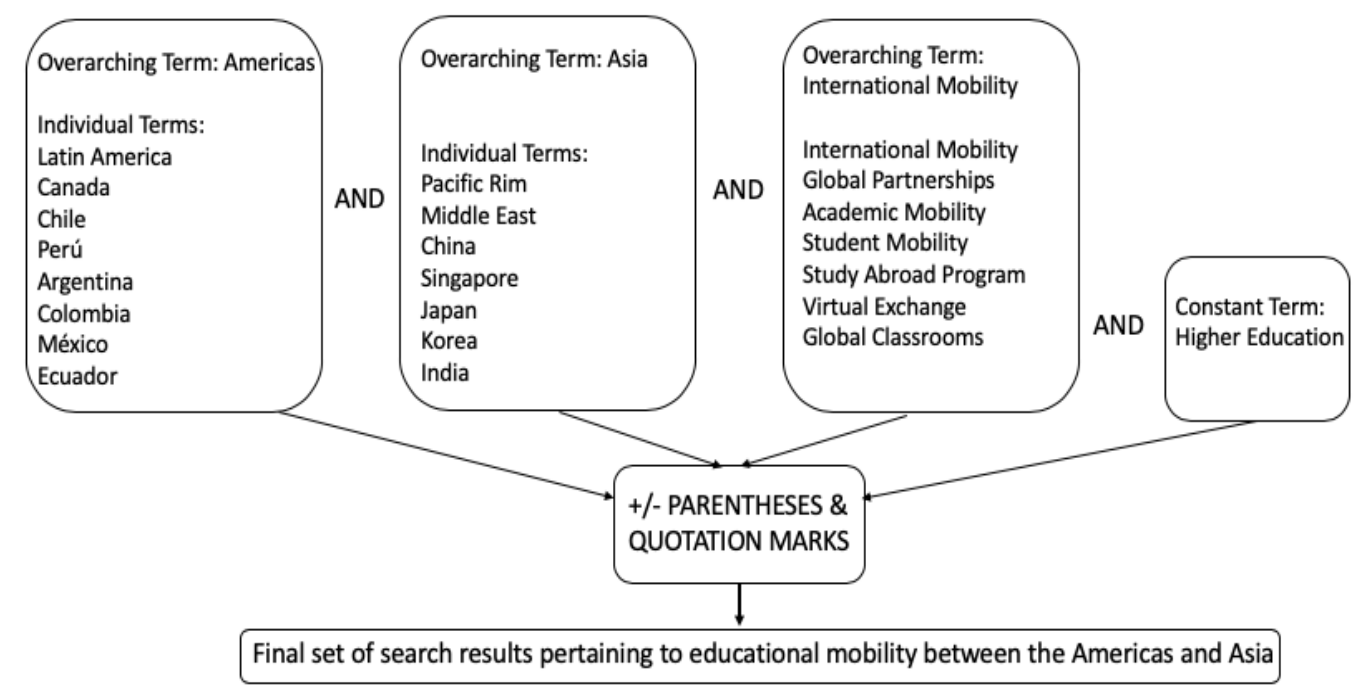

Figure 1. Depiction of the search strategy utilized

Our criteria stated that articles had to include information about the physical or virtual mobility of students, academics, or higher education administrative staff between the Americas and Asia. The articles also had to be published in peer-reviewed journals or be papers published by organizations that promote collaboration between these regions in either English or Spanish within the last twenty years. 
In line with the PRSIMA Group's framework (Moher, Liberati, Tetzlaff, Altman, \& The PRISMA Group, 2009), we developed eligibility criteria based on content, study characteristics, year, language, and publication status. Upon the review of the articles and further discussion with a fourth author, the exclusion criteria were determined. In line with these criteria, articles discussing student mobility solely within Asia, between Europe and Asia, or between Asia and Oceania were excluded; articles discussing only student mobility between Asia and the US were excluded as well. The world-wide recognition of the exceptional quality of education and research in the U.S., as measured by international rankings, is the main pulling force in attracting many more students from Asia than other American republics (UNESCO Institute of Statistics, 2020). These unique characteristics are not shared by the rest of the continent, and would confound our findings related to Latin America and Canada. Therefore we chose to exclude the US to focus on the rest of the American continent where Asian student mobility is less common. We also excluded articles about international student mobility in settings that do not pertain to higher education, such as long-term migration, language institutes or secondary schools. Non-primary sources such as literature reviews or viewpoint articles were also excluded.

Two authors screened the titles and abstracts of our search results and removed the duplicates and then read through the full text of all articles that met the criteria. A reference list review was also carried out for articles that met both the inclusion and exclusion criteria. Cited works from articles that met the inclusion and exclusion criteria were reviewed using the same methodology before finalizing the results. A search was also completed to identify relevant reports published by agencies who have ties to Higher Education Mobility in Asian and Latin American countries such as The World Bank, United Nations Educational, Scientific and Cultural Organization (UNESCO); The Asia-Pacific Economic Cooperation (APEC), The Association of International Education Administrators (AIEA), The Japan International Cooperation Agency (JICA), The Asean University Network, The Institute of Korean Culture at Korea University, and The U.S.-China Economic and Security Review Commission. Their results were also included.

Spreadsheets were used at each phase to extract and organize relevant information. Full articles were classified based on general study characteristics such as experimental, quasi-experimental, one group, correlational, case study, and editorial. A thematic analysis of the findings was conducted on all included sources to identify recurrent themes used to describe factors that influence the participation of students among the synthesized mobility programs.

\section{Results}

Our search yielded 364 initial results after totaling the results from each database. An additional 62 results were considered after the reference list review. We based our scoping review on Moher, Liberati, Tetzlaff, Altman, and The PRISMA Group's framework (2009) and included a PRISMA flow diagram (Figure 2) below. After removing duplicates, 411 articles remained. We conducted a review of these 411 abstracts to determine whether the articles met our inclusion criteria. 56 articles passed onto the article review phase. In this phase, we read the entire article to see if the content matched our inclusion criteria. 11 articles discussed regional mobility among only Asian countries or between Asia and Europe, therefore these articles were excluded. Six articles were excluded because they discussed mobility between the US and Asia and one was excluded for discussing international student mobility regarding language institutes. Another five were excluded because they were classified as viewpoint articles. The remaining 30 articles and three reports were organized based on study design. 


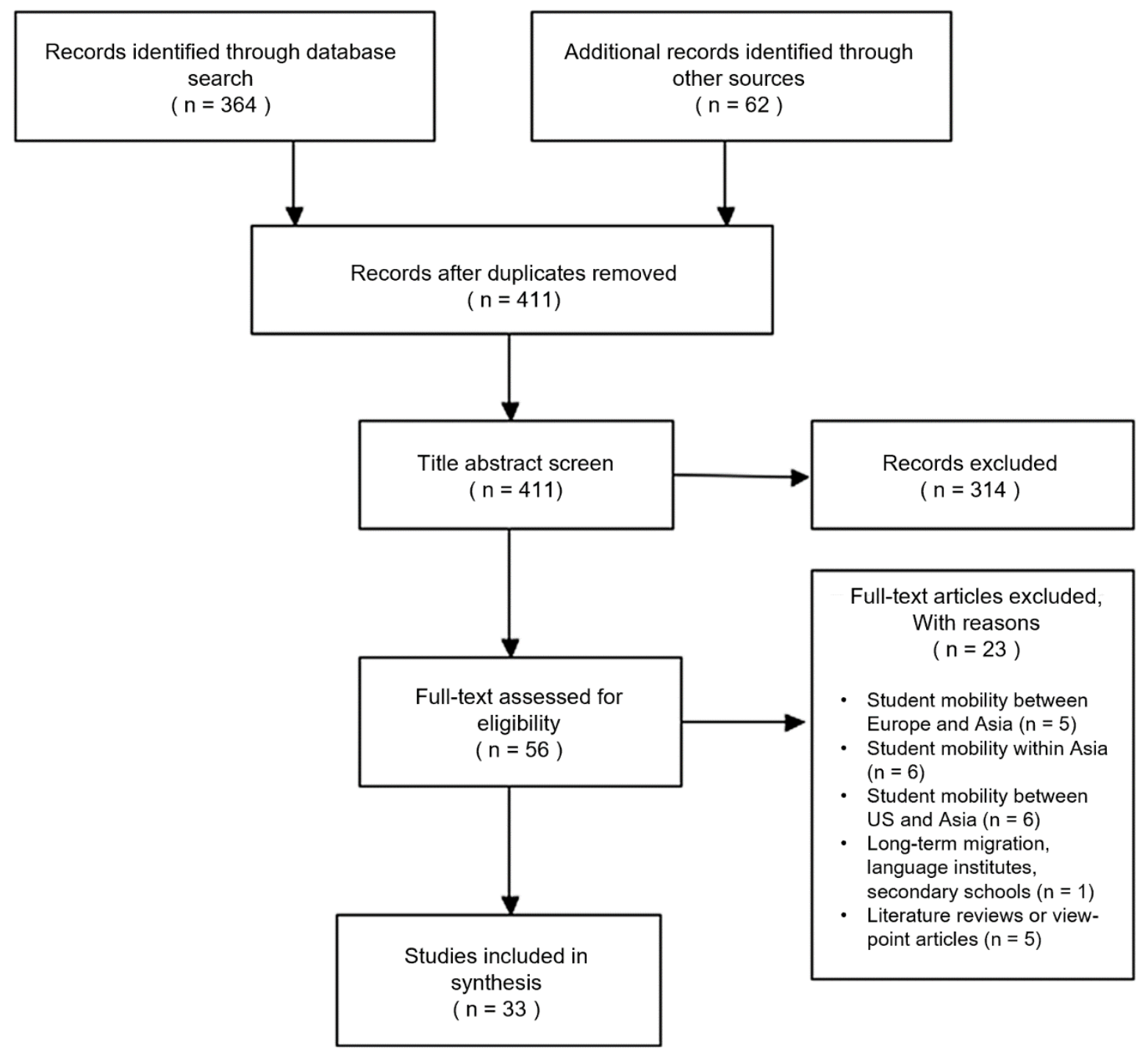

Figure 2. PRISMA flow diagram summarizing search results

The 33 studies in our synthesis included eight that focused on inter-continental mobility between Latin America and Asia, while most others involved mobility between Asia and Canada. We examined the study methods to gain a deeper understanding into the nature of the existing data on this subject and found no studies that could be classified as experimental or quasi-experimental.

Eleven sources applied empirical methods. Five articles and two reports analyzed existing datasets on university programs, student composition, or rankings. Three articles and one report used quantitative surveys to determine or examine factors that influence study abroad.

Out of 18 solely qualitative studies, 11 articles were based on student interviews. Most were semi-structured, and all were either transcribed or recorded. The commentary was reviewed to highlight specific themes transient across the group studied. Two articles distributed surveys that allowed students to respond to questions about their experiences in an open-ended manner. The questions would ask about specific cultural, economic, logistical issues. Three articles used a combination of these methods. One article was based on classroom observations. In addition, two articles included personal anecdotes shared as journal entries or recorded dialogue as part of their data.

Four studies applied mixed methods-combining dataset analyses with student interviews.

Each of the themes identified among the synthesized publications described factors that, depending on the context, were associated with either inhibiting mobility or contributing to it as an enabler. In the following paragraphs, we 
describe the specific scenarios of each of the main factors discussed in the articles and how each of these can act as a barrier or in other situations promote mobility. The order of the themes follows the frequency in which they appeared in our findings.

\subsection{Cultural Factors}

Twelve articles discussed cultural reasons that influence mobility initiatives between Asia and the Americas. Though five of these regarded culture as a significant barrier, eight articles identified ways in which culture can also enable these experiences.

Cultural differences had a negative impact on the comfort level experienced by students who made the leap. Issues related to adjusting food habits, finding accommodation, and dealing with isolation from local communities have all been recorded (Hagley \& Cotter, 2019). Different perceptions of race and skin color caused Canadian students to receive unwanted attention from individuals in Mainland China, making them uncomfortable (Trilokekar \& Kukar, 2011). On the other hand, Korean students in Canada also expressed that they felt uncomfortable with Canadian ethnocentrism, which caused Canadians to treat Koreans as inferior (Bilash \& Kang, 2007). Cultural misunderstandings regarding how the Korean teachers addressed their group leader as well as their lack of emotional expression also caused problems while in Canada (Bilash \& Kang, 2007). Students also remarked that there were many instances where they were unfamiliar with the host culture and they were unprepared to handle the shock. (Douglas, 2020). As such, students wary of these differences may think twice about going abroad, while intrepid students who venture out may be unprepared and risk feeling unwelcome, discriminated against or misunderstood by their hosts in either Latin America or Asia.

Alternatively, the desire to experience a new culture pushed students to pursue an exchange program. For example, some undergraduate students from Canada cited a desire to experience Turkish culture as their pre-departure reason to study abroad in Turkey (Kondakci, 2011). Chinese students were also interested in learning Spanish to understand Latin American culture, so private institutions in Mexico collaborated with Chinese, Korean, and Japanese institutions to provide special courses (Aupetit, 2019). Korean youth in Canada attached a more practical reason for learning about the culture, deeming their experiences as a mechanism to grow their "cultural capital" and explained that experiencing discrimination and being of a minority in their host country provided an opportunity for them to reevaluate their priorities and attitudes regarding race and privilege (Chun \& Han, 2015). These accounts of students seeking contrast serve as examples of horizontal mobility that exists between these regions (Teichler, 2017). The finding that choosing a less familiar destination was positively associated with skill development and sense of career impact (Farrugia, 2017) may serve to further explain this attraction and ultimately, illustrates that horizontal mobility also serves to bolster the value of education.

The perception of a safer environment in the host country is a specific kind of cultural difference that attracts students. Indian students in Canada valued the opportunity to explore a new, unique environment in a safe setting (King \& Sondhi, 2018). The perception of safety in the host culture was also an important consideration for Chinese students, who chose Canada as a study abroad destination rather than the U.S. due to the U.S. media's portrayal of students as violent (Zwart, 2013). Although an exotic element can act as an enabler of international student mobility, safety is also required. In one example, virtual exchange permitted students to explore the unknown while taking a need for safety out of the equation and simultaneously mitigating culture shock. Japanese and Colombian students participating in a virtual exchange program noted that they found the program meaningful because it contributed to their understanding of another culture, particularly one they had been interested in, but were unable to learn much about in their home country (Hagley \& Cotter, 2019).

Certain characteristics of Asian culture help students from this part of the world gather family support for study abroad. In China, Confucianism is the center of all education. Under its philosophy, education has been a pathway to officialdom and filial piety is of extreme importance. Thus, Chinese parents are heavily involved in the decision for study abroad for their children; and familial support was highly ranked as an enabler for international study among Chinese students (Zwart, 2013). Indian students were also influenced by their families (King \& Sondhi, 2018; Walton-Roberts 2015) to study abroad in Canada. Specifically, Indian families encouraged female children to go abroad after an Indian societal shift determined nursing to be a suitable profession for women (Walton-Roberts, 2015). On the other hand, differences in customs made Mexican families wary of sending their children to Asia, out of "fear of the unknown" (Aupetit, 2019). Considering that most students depend on their family's resources, local culture and family opinion are significant factors in choosing study destinations or in deciding whether students will study abroad in the first place. 


\subsection{Academic and Professional Factors}

Thirteen of the finalized papers cited academic or professional reasons as an impetus for student mobility. From the reviews discussing factors related to academics or professional reasons for studying abroad, seven of the articles cited the possibility of better job prospects as a reason (Chen, 2006; Chun \& Han, 2015; Figueroa, Morales, \& Sharma, 2012; Furukawa, Shirakawa, \& Okuwada, 2012; King \& Sondhi, 2018; Walton-Roberts, 2015; Zwart, 2013).

Our review revealed that from an Asian perspective, Latin American institutions seemed to be at a disadvantage in two key areas when compared with alternatives in other regions. For example, although doctoral education is deemed a "very important" part of the internationalization strategy for both Latin American and East Asian institutions, only three percent of Latin American universities were centers of both teaching and research (Jørgensen, 2012). This also explains why, in the past, only two percent of Latin American joint-research studies were conducted with Asian HEIs (De Wit, Jaramillo, Gacel-Ávila, \& Knight, 2005). This lack of research centers may prevent students who are in research-intensive fields to explore learning opportunities in Latin America. Another barrier to mobility between the regions that emerged in our findings was the difference in academic environment. One study found that Latin American and Asian institutions have education systems that differ in their competitiveness and capacity to educate in STEM related academic fields, and suggests that Asian students used to an intense, competitive, and rigorous system, may not see the benefit of switching to an education system where the competitiveness and quality of STEM is lower (Lopez-Leyva \& Rhoades, 2016).

The perception that universities abroad can provide a better standard of education or strengthen job prospects can encourage mobility between these continents. The effect that university rankings and the perceived value of a foreign degree had on the decision to study between Asia and the Americas was emphasized in six of the included studies (Chen, 2006; Furukawa et al. 2012; King \& Sondhi, 2018; Liang-Hsuan, 2006; Perna, Orosz, Jumakulov, Kishkentayeva, \& Ashirbekov, 2014; Zwart, 2013). For example, Liang-Hsuan found that "the foreign degrees are prestigious or valued by [their] home country" by many students (Liang-Hsuan, 2006). Furthermore, HEIs that boast factors associated with a good quality of education such as perceptions of better faculty abroad (Figueroa et al., 2012) and a more personalized teaching style (Bilash, 2019) may attract more international student mobility, particularly on behalf of students that endure poor quality of education in their country of origin (Perna et al., 2014). Similarly, our findings show that student mobility is further encouraged when the job prospects in their country of origin are bleak (Furukawa et al., 2012) and when there are better international job prospects with a foreign degree (Chen, 2006; Figueroa et al, 2012; King \& Sondhi, 2018; Walton-Roberts, 2015). International students felt that a foreign education would bolster their future job applications and careers (King \& Sondhi, 2018). Chinese students specifically believed that Mexican education would provide them an opportunity to obtain internships at Mexican companies in Asia (Aupetit, 2019). These findings reinforce the idea that vertical mobility, as described by Teichler (2017), is also an important driving force behind the student mobility between these parts of the world.

\subsection{Linguistic Factors}

Communication is a necessary aspect of any experience. As such, nine articles cited language as either a barrier or enabler for academic mobility. Six articles discuss language as a hindrance to student success, while three discuss the chance to learn a language as a driver.

In the context of language as a barrier, the University of British Columbia immersed their Chinese international students immediately into an English curriculum. As such, students had difficulty understanding and participating in the classes (Fang, Clarke, \& Wei, 2016). Chinese scholars also stated that the biggest barrier for them to fully understand and enjoy courses at their host institution was insufficient English language proficiency, which hindered their communication and ability to understand lessons (Guo \& Wei, 2012; Lu \& Han, 2010). Some program participants also noted that they had difficulty adjusting because the study of the English language was different in rural areas of China (Vasilopoulos, 2019). An issue specifically with Latin American and Central Asian HEIs was that programs were offered in the local language (Ruiz-corbella \& Álvarez-González, 2014). This may pose a problem for Latin American students who wish to study in a Central Asian institution because the languages utilized are encountered less frequently, and thus students would have had little previous exposure. These same institutions also did not show specific information about exchange programs on websites in a language beyond the local language. A foreign student would certainly have problems trying to find relevant information if they were considering the option of studying there virtually or in-person (Ruiz-Corbella \& Álvarez-González, 2014). Thus, language barriers can act in preventing students from accessing an educational program or may dampen their experience.

Nonetheless, a need for language proficiency also drove many students to study abroad in an English-speaking country in the first place. Students choose Canada as a location to experience an immersive English environment and to better 
help them adapt to their English studies (Kato \& Reeder, 2015; Rhein \& Jones, 2020). They also studied in Canada to improve their English in order to appear authoritative in a research setting. One student remarked that imperfect English would undermine her academic authority (Morley, Layton, \& Hada, 2019). However, Korean students specifically wanted to speak English with a North American accent, improve their vocabulary, and use English idioms naturally and effortlessly in order to improve confidence. This stemmed from a desire to speak without frustration or fear of embarrassment (Chun \& Han, 2015). As such, the rationale goes beyond just a reason to further an academic goal, but is instead, more personal. Only one article alluded to an interest in learning Spanish as a motivating factor for Chinese students (Aupetit, 2019).

\subsection{Economic Factors}

The cost of studying abroad affected international student mobility and was mentioned in eight of the reviewed studies, despite the fact that most undergraduate exchange students benefit from tuition waivers at the host institutions. As expected, students intending to return home after their programs were deterred by high tuition fees (Perna et al., 2014). However, the high cost of a foreign degree may not necessarily be a barrier to international student mobility. A higher cost of education, that takes into account expenses for living abroad, was considered a barrier for international student mobility amongst first-time graduate students (Figueroa et al., 2012). International students from low-income families funding their university fees and living expenses through a combination of parental support, grants, bursaries, part-time work, and savings, had difficulty financing their studies and lives abroad regardless of whether they were undergraduate or postgraduate students (Chun \& Han, 2015; King \& Sondhi, 2018).

Although the cost of education is a crucial factor, according to some studies international students acted in accordance with the human capital theory, whereby the perceived benefits were worth the costs (Perna et al., 2014). In particular, the high cost of tuition was also seen as an indicator of high wages in the future, which helped encourage students to study abroad in universities with a higher cost of tuition, especially those with plans to stay indefinitely (Kumar, 2015).

\subsection{Program Structure}

Six articles elaborated on how program structure can encourage or prevent mobility. Five articles identified negative aspects to programs which inhibited student participation, and one article discussed a structure that contributed to success. In some institutions, students were disappointed by a lack of systematic support and structure for obtaining academic guidance or mentorship. Furthermore, in some cases, access to this type of support was unavailable to most participants (Guo \& Wei, 2012). One structural limitation of programs offered by Latin American and Central Asian HEIs is that there is little standardization in terms of programming. They are guided by many co-existing concepts that define distance education and Virtual Mobility in terms of flexibility, accessibility and the methodology used (Ruiz-corbella \& Álvarez-González, 2014). For example, the requirements for synchronous "face-to-face" involvement can range from as little as three to as many as 200 hours. In Latin America, these distance education programs do not usually cater to face-to-face interaction, and as a result, many are not yet fully recognized (Ruiz-corbella \& Álvarez-González, 2014). Other logistical issues with virtual mobility programs that affected student success included technical difficulties such as problems uploading information and using the internet (Hagley \& Cotter, 2019). Access to information is another obstacle that emerged. One article cited a lack of current information available online about international student experiences, student-faculty communication, and online study opportunities at Thai universities as a great barrier to student mobility towards this region (Snodin, 2019). While a lack of information, academic support and standardization among higher education programs can prevent mobility, the presence of extracurricular activities help promote it. One Canadian study described how field trips to destinations ranging from museums to zumba classes created memories beyond academic life. These were frequently recalled with positive emotions when students reflected on their experiences and were especially valued as opportunities to interact more with the local community (Douglas, 2015).

\subsection{Political Climate}

Policies implemented by governments have both encouraged and hindered HEI mobility amongst students. Three articles discussed this theme as a limitation to international student mobility, while four found that it could encourage mobility.

Policies that restrict immigration or trade, regulate foreign direct investments (FDI) or place certain requirements established by grant programs were found to hinder mobility. Some students' choice of destination was encouraged by international migration opportunities for both themselves and their families (King \& Sondhi, 2018; Walton-Roberts, 2015). As such, policies which seek to reduce immigration may dissuade students from studying abroad. Trade barriers including regulations that limit student visas as well as other immigration issues were also found to play a part in 
influencing foreign study (Perna et al., 2014). There is a restrictive FDI regime in India that discourages foreign universities from setting up branch campuses, in order to protect the competitiveness and attractiveness of local Indian universities. This policy may contribute to the lack of interest in this region as a destination for international students (Kumar, 2015). Kazakh students' participation in study abroad programs to the Americas was influenced by the governmental requirement that recipients return and work in Kazakhstan for five years after study abroad program completion. Some students opted out of the program to avoid this requirement (Perna et al., 2014). These types of policies, whether or not they directly involve education, were found to limit mobility.

On the other hand, policies that were found to favor mobility may be national in scope or actively encourage cooperation between countries. Cooperation policies encourage international mobility by helping students shoulder the burden of the financial costs of studying abroad (Perna et al., 2014) or by fostering a system of academic partnerships (Kumar, 2015). The Chinese government, for example, particularly desires to influence the perceptions of China held by leaders of Latin America and the Carribean, which is why it has established and funded nearly 60 Latin American and Carribean regional centers based in Chinese research centers and universities to deepen its expertise of this region (Kolesk, Blivas, \& United States-China Economic and Security Review Commission, 2018). These types of initiatives encourage mobility, although they are heavily reliant on the political advocacy and diplomatic relations of countries as well as motivation inspired by authorities (Kumar, 2015). At the national level, policies that promote autonomy among higher education institutions (HEIs) were found to be enablers. Particularly, HEIs in Chile share more autonomous governance structures, something they have in common with HEIs in Asia. This opportunity to adjust to market needs allows for the kind of agility that would be necessary for new collaborations across these two regions (Segrera, Brock, \& Sobrinho, 2009).

\section{Discussion}

Based on the findings, we propose some solutions which could be taken into consideration to improve the quality of exchange programs and enhance student experiences.

\subsection{Overcoming Cultural Differences}

Regarding ways to overcome cultural differences, a few suggestions were offered explicitly in the articles reviewed, while others can be inferred from the limitations themselves.

Our review found that family relations are a significant factor in enabling students to study abroad. This can take many forms, from families putting pressure on children to obtain a good education aligning with cultural goals, or providing economic support, to seeking alternate pathways towards immigration (Zwart, 2013; King \& Sondhi, 2018). With so many direct familial influences, it would be highly relevant for universities to consider the family perspective in their efforts to promote mobility programs, communicate with their priorities and concerns in mind, and even prepare marketing material focused on highlighting how the entire family may benefit economically and culturally from these experiences.

Our findings suggest that when advertising these exchange programs, universities could choose to portray them as a type of adventure, in addition to an academic experience. Based on the findings that suggest some students that travel to pursue study between these two continents are hoping to experience a new environment (King and Sondhi, 2018) and also see themselves as the adventurer in a different country, a program may seem more appealing if framed as a venture into the unknown, mediated by rich academic experience. Emphasizing how programs specifically leverage cultural contrasts to build skills needed for employment, may help higher education programs differentiate themselves from the alternative of simply travelling.

\subsection{Overcoming Language Barriers}

Access to websites translated in a variety of languages may help overcome the obstacles associated with language, by making specific information on the program accessible to foreign students and their families. Latin American institutions could consider having translations available for popular Asian languages such as Mandarin, Korean, Japanese, and Hindi.

Pre-departure training in the local language could also be of great help, as students would have some ability to communicate before engaging in the program and would not feel overwhelmed from the start. As many students also expressed frustration in their ability to keep up with foreign curriculums due to language barriers, it would be beneficial to ensure that translations of class lectures are accessible if need be. In addition, Chinese students were able to overcome language barriers after socializing more with English-speaking friends instead of associating exclusively with Chinese companions. Therefore, there should be activities that promote interactions with local students instead of 
solely grouping international students together. Socialization will strengthen conversational and written skills by teaching students colloquialisms to improve their language proficiency through enhanced exposure (Lu \& Han, 2010).

The English language is also important to Latin American institutions as well. In order to study the political and economic relationships between Asia and Latin America, solid expertise in the discipline in addition to the English language is necessary (Ramírez Bonilla, 2016). Therefore, Latin American HEIs need to dominate English in order to bring an understanding of Asia to Spanish-speaking audiences, which would foster further relations with Asian institutions and help internationalization. This step could begin specifically by increasing the English capabilities among faculty, academics, and students at HEIs.

\subsection{Bolstering Academic and Professional Benefits of Mobility}

Access to resources such as academic advisors is relevant considering that international students can sometimes be overlooked when mixed in with the domestic students. Institutions could consider setting aside different academic advisors for international students. These advisors can provide guidance on issues specific to being an international student.

A barrier to Latin American cooperation with Korean HEIs specifically is the lack of funding. Increased cooperation with Korean institutions such as the Korea Foundation or Korea Research Foundation would allow for further development of Korean studies and introduce funding to this sector in Latin America (Di Masi, 2005). As for lack of investment in doctoral programs, one potential solution could be for universities to adopt a more flexible approach to collaboration and funding, which might result in more opportunities to invest in doctoral education in Latin America (Jørgensen, 2012).

Students also attended prestigious universities due to the perceived value of their degree and the ability of this degree to aid their future profession. This perceived value is often formulated from the university rankings. Rankings matter a significant amount to students, but it is impractical to assume that Latin American institutions, who have rarely been top 500 in international higher education rankings, can suddenly change their position to attract students. To force these institutions to change to cater to a model which the rankings are heavily biased towards a sole model of higher education- the elite, US research university- causes them to sacrifice their individual and national character as institutions. From our findings, we see that this character, which introduces culture, is quite another important factor, perhaps just as important as ranking. As a result, instead of focusing on catering to rankings, it may be worthwhile to invest in displaying the university's other achievements in order to attract students. For example, a focus on the humanistic and societal missions of higher education is clearly absent from the ranking criteria, but Latin American universities tend to excel in these areas (Marope, Wells, \& Hazelkorn, 2013).

Policies which advocated for greater job opportunities and encouraged immigration also encourage more international student mobility. But policymaking is a larger macro factor that is not easily tackled. However, due to its overarching effect on a large number of students, it is important to consider. Policymakers should work towards creating more attractive immigration policies (Figueroa et al., 2012) or global partnerships to ensure an influx of foreign students. To address the concerns about credit transfer (Aupetit, 2019), policies can include a standardization of the credits system such as the European Credit Transfer and Accumulation System (ECTS), which allows for a transparent process of collaboration between countries (European Union, 2020). Standardization of programs and coursework can also promote efficiency which could pave the way for future virtual and in-person collaborations.

International students felt that high tuition fees were not an overly steep price to pay in exchange for advancing their economic status in the future. Therefore, economic reasons were not as much of a barrier. However, since only students who had already studied abroad were the focus of all the research, students who wished to study abroad but were financially unable to do so were not included in the research. The financial cost of studying abroad may be a strong factor in determining international student mobility amongst students with low financial capabilities. Parents were willing to bear the financial burden for their children to study abroad, but this led to the students feeling additional stress towards their finances (Chun \& Han, 2015). Such financial burdens and stressors can be reduced by scholarships and bursaries provided by educational or government institutions.

Academic rankings and the perceived quality of education to students are important factors in choosing a study destination (Liang-Hsuan, 2006). However, high academic rankings leading to a better perception of the schools may result in the schools being more popular and widely known, resulting in more students being interested in studying there. Lesser-known schools should seek to increase their influence through advertising to a wider global audience or by participating in global academic partnerships. Universities can also aim to have campuses abroad to reach out to foreign students and gain greater name recognition. 


\subsection{Improving Students' Well-Being}

Student's well-being should always be a key concern when encouraging international student mobility. This can be achieved through pre-departure initiatives that ameliorate culture shock, targeted actions to make host institutions more welcoming to different types of students and quality mentoring programs. Strong mentor and academic support was found to boost the well-being of international and local students and also bolster support for student mobility in both directions (Guo \& Wei, 2012).

Studies included in our review suggest the importance of including opportunities to familiarize students with the host culture before departure. The greatest barrier students experienced when travelling between Asia and the Americas was the unfamiliarity with the native customs. Therefore, it is of utmost importance to inform the students of the situations they may encounter and how to handle uncomfortable scenarios before they happen. Informational sessions and training programs could be provided well before the students arrive to provide access to common questions to prepare them for the jump between cultures and prevent culture shock (Clarke, Fan, Webb, \& Zou, 2020). Similarly, our findings suggest that including activities and procedures to help ensure safety is advisable since safety was found to be an important concern among students and families considering these inter-continental study opportunities.

Our findings also identified several ways that host universities can be more welcoming. It is necessary that staff also understand that culture permeates into student's personalities. Students had said that they genuinely felt uplifted when instructors asked about their opinions and well-being, so university staff should engage in this type of conversation to empathize with students who are in an unfamiliar environment (Clarke et al., 2020). In addition, there should be open communication to discuss any situations where students feel uncomfortable, as it will allow for growth and development on both sides (Bilash \& Kang, 2007). Misunderstandings may be common, and should not be punished. Participation in extracurricular activities beyond those associated with academia was found to be of particular importance since these activities provide an opportunity for students to make positive memories while also interacting with the community (Douglas, 2015). Extracurricular activities are beneficial to students' well-being and add value to their experiences abroad. Involvement in local cultures and communities through such extracurricular activities can also prevent the isolation often faced by international students in foreign communities (Hagley \& Cotter, 2019). Finally, since safety is crucial to a student's decision to study abroad (King \& Sondhi, 2018; Zwart, 2013), providing a safe environment conducive to studying is an important way to promote wellbeing and encourage international student mobility.

\subsection{Higher Education Mobility during the COVID-19 Pandemic}

The pandemic has placed health security and safety at the forefront of factors to consider and initiated a global shift towards virtual mobility. Overall, many Asian students showed no interest in studying abroad after the pandemic, and if they were to go abroad, they prioritize East Asian countries with a better economic situation and pandemic control (Xiong et al., 2020). This limits the ways in which Latin American countries (LACs) can provide overseas opportunities to these students, as there is a lack of interest in the region due to an inability to travel. This indicates that universities should focus on the virtual learning aspect of international student mobility for the time being and find ways to make these opportunities more appealing to students.

The extent to which these virtual internationalization efforts will succeed depends largely on administrative leadership, structure, and staffing throughout the university (Bruhn, 2020). In general, universities must prepare for the logistical problems surrounding an online education system. Especially as students may be in different time zones when considering international universities, it is important to align learning-assessment procedures and criteria with the new online curricula. One example of this is changing the grading system to pass or fail. A strengthening of academic and psychological support had also been suggested for in-person mobility programs, but this suggestion is even more imperative in the current context when considering that students may struggle now to adjust to an online environment (Bruhn, 2020). Difficulties delivering learning content to students in China because of internet censorship and the inaccessibility of popular online platforms is also a concern to be addressed (Zhang, 2020).

\section{Limitations}

Although this review seeks to provide some insight into understanding barriers and enablers of international student mobility between Latin America and Asia, there are several limitations which should be taken into account when evaluating the findings.

First, most of the studies done cross-continentally between Asia and America were not specific to programs that involve solely Latin America and Asia. Thus, findings from this review may not be accurately generalized or be readily applicable for international student mobility between these two continents. Out of the 33 articles used in the review, 
only 8 included mobility between both Latin America and Asia, while most others focused on mobility between Canada and Asia. Furthermore, these studies included only larger Asian or American countries. Consequently, many countries with fewer direct interactions with the other continent remained unmentioned.

Second, our search parameters were only in English, which could overlook relevant articles written in Spanish or Asian languages. Despite our search across 6 major electronic databases, the majority of included articles had an East Asia focus. The lack of representation amongst other regions may prove to be a hindrance in extrapolating our results to the region of continental Asia.

Lastly, articles mainly focused on international students with minimal information on students who wished to study abroad but were unable to do so. Their perspectives may add depth to future research on this topic.

\section{Conclusion}

This review highlights the overall dearth of research into cross-regional student mobility between Latin America and Asia with the hope that this paves the way for future efforts to gain insight into international student mobility between these two regions. The findings of this scope review provide a succinct baseline of factors that may promote or inhibit international student mobility and provide suggestions for both parties involved to deconstruct barriers to internationalization. Nonetheless, additional research is needed to better understand factors that undermine these types of programs and explore the barriers faced and decisions made by students who express a desire to go abroad but have not done so. The results of this scope review can serve as guidelines for further development of programs especially in academic institutions throughout Latin America that may benefit from strategies that highlight their contributions and achievements in the social sphere while strengthening the flow of communication with the broader international community.

\section{Acknowledgements}

We would like to thank Jose Luis Parra, Director of the Pacific Alliance Observatory and the Confucius Institute at UC-Chile for reviewing our manuscript and providing suggestions as well as Dr. Johannes Rehner, Professor of the Geography Institute; Jorge Sahd and Diego Rojas Toro from the Center for International Studies, and Ana María Sepulveda, Director of International Partnerships and Development at UC-Chile for their time and discussions that helped inspire this work. Jolene Singh, Research Assistant at the Columbia University Medical Center, contributed with much appreciated proofreading. Finally, we would like to thank Chris Molinari and the Columbia University Global Center, Santiago for initiating this partnership between Pontificia Universidad Católica and Columbia University.

\section{References}

Asian Infrastructure Investment Bank \& The Economist Intelligence Unit. (2019) ASIAN INFRASTRUCTURE FINANCE 2019 Bridging Borders: Infrastructure to Connect Asia and Beyond. Retrieved August 14, 2020, from https://www.aiib.org/en/news-events/asian-infrastructure-finance/common/base/download/AIIB-Asian-Infrastru cture-Finance-2019-Report.pdf

Aupetit, S. D. (2019). La internacionalización de las universidades mexicanas hacia Asia del Este. Perfiles Educativos, 4l(163), 138-155. https://doi.org/10.22201/iisue.24486167e.2019.163.58842

Bilash, O., \& Kang, J. (2007). Living Well in a Changing World: What Korean Teachers of English say About a Study Abroad Program in Canada. The Journal of Educational Thought (JET) / Revue De La Pensée Éducative, 41(3), 295-309. Retrieved July 18, 2020, from www.jstor.org/stable/23765524

Bilash, O. (2019) Study abroad, transformation, and ikigai: A case study. FIRE: Forum for International Research in Education, 5(2). https://doi.org/10.32865/fire201952170

BIZ Latin Hub. (2020.) Latin America and Asia Offers Great Potential for Business Connectivity. Retrieved August 14, 2020, from https://www.bizlatinhub.com/latin-america-and-asia-offer-great-potential-for-business-connectivity/

Boston College Center for International Higher Education. (2016). Catholic Universities: Identity and Internationalization, A Pilot Project. Retrieved August 14, 2020, from https://www.bc.edu/content/dam/files/research_sites/cihe/pubs/CIHE\%20Perspective/CIHE_Perspectives_No3. pdf

Bruhn, E. (2020). Virtual Internationalization in Higher Education. Wbv Media. https://doi:10.3278/6004797w

Casallas, L. (2010). Where Do Latin American Students Choose to Study? Retrieved August 27, 2020, from https://www.qs.com/latin-american-students-where-do-they-choose-to-study/ 
Chen, L. (2006). Choosing Canadian graduate schools from afar: East Asian students' perspectives. Higher Education, 54(5), 759-780. https://doi.org/10.1007/s10734-006-9022-8

Chun, J. J., \& Han, J. H. (2015). Language Travels and Global Aspirations of Korean Youth. Positions, 23(3), $565-593$. https://doi.org/10.1215/10679847-3125913

Clarke, A., Fan, X., Webb, A., \& Zou, W. (2020). Becoming, belonging, and between: Unexpected outcomes and curricular implications for study abroad. Teaching and Teacher Education, 90, 103031. https://doi.org/10.1016/j.tate.2020.103031

De Wit, H., Jaramillo, I., Gacel-Ávila, J., \& Knight, J. (2005). Higher education in Latin America. The international dimension. Washington, DC: World Bank. https://doi.org/10.1596/978-0-8213-6209-9

Di Masi, J. R. (2005). The Challenge of Developing Korean Studies in Latin America. Conference. Current trends and Future Objectives of Korean Studies. Organized by the International Center for Korean Studies, Institute of Korean Culture, Korea University, Seoul, Korea. July, $2005 . \quad$ from https://ddd.uab.cat/pub/hmic/16964403n4/16964403n4p97.pdf

Douglas, S. R. (2015). Student perspectives on a short-term study abroad experience. In P. Clements, A. Krause, \& H. Brown (Eds.), JALT2014 Conference Proceedings. Tokyo: JALT.

Douglas, S. R. (2020). Counterfactual Understandings: What Japanese Undergraduate Students Wish They Had Known Before a Short-term Study Abroad Experience. Teaching English as a Second or Foreign Language, 23(4). Retrieved August 14, 2020, from http://tesl-ej.org/pdf/ej92/a2.pdf

Estevadeordal, A. (2018, March 22). Latin America in the new Asia-Pacific trade order. Retrieved August 14, 2020, from https://www.brookings.edu/research/latin-america-in-the-new-asia-pacific-trade-order/

European Union. (2020). European Credit Transfer and Accumulation System (ECTS). Retrieved August 14, 2020, from

https://ec.europa.eu/education/resources-and-tools/european-credit-transfer-and-accumulation-system-ects_en

Fang, W., Clarke, A., \& Wei, Y. (2016). Empty Success or Brilliant Failure: An Analysis of Chinese Students' Study Abroad Experience in a Collaborative Master of Education Program. Journal of Studies in International Education, 20(2), 140-163. https://doi.org/10.1177/1028315315587106

Farrugia, C., \& Sanger, J. (2017) Gaining an Employment Edge. The Impact of Study Abroad on 21st Century Skills \& Career Prospects in the United States. IIE Center of Academic Mobility Research and Impact. Retrieved December $\quad 08, \quad 2020, \quad$ from https://www.iie.org/en/Research-and-Insights/Publications/Gaining-an-Employment-Edge---The-Impact-of-Stu dy-Abroad

Figueroa, C. I., Morales, B., \& Sharma, A. D. (2012). International student mobility: Trends in first-time graduate enrollment. Journal of Academic Administration in Higher Education, 8(2), 55-63.

Friedman, G., \& Mauldin Economics (2017, April 01). 3 maps explain why South America is politically isolated. $\begin{array}{llll}\text { Retrieved } \quad \text { August } & 14, & 2020,\end{array}$ https://www.businessinsider.com/maps-explain-south-america-political-isolation-2017-3

Furukawa, T., Shirakawa, N., \& Okuwada, K. (2012). An empirical study of graduate student mobility underpinning research universities. Higher Education, 66(1), 17-37. https://doi.org/10.1007/s10734-012-9586-4

Grove, J. (2020, March 12). 'Major disruption' to student mobility from coronavirus feared. Retrieved August 14, 2020, from https://www.timeshighereducation.com/news/major-disruption-student-mobility-coronavirus-feared

Guo, L., \& Wei, W. X. (2012). Visiting scholars: Facilitators of sustainable international strategic alliances in higher education. Journal of International Business Education, 7, 181-198.

Hagley, E., \& Cotter, M. (2019). Virtual exchange supporting language and intercultural development: Students' perceptions. CALL and Complexity - Short Papers from EUROCALL 2019, 163-168. https://doi.org/10.14705/rpnet.2019.38.1003

Holm-Nielsen, L., Thorn, K., Brunner, J. J., \& Balán, J. (2005). Regional and international challenge to higher education in Latin America. In H. De Wit, I. Jaramillo, J. Gacel-Ávila, \& J. Knight (Eds.), Higher education in Latin America. The international dimension, (pp. 39-69). Washington, DC: World Bank. 
Jørgensen, T. E. (2012). CODOC - Cooperation on Doctoral Education between Africa, Asia, Latin America and Europe. Brussels: European University Association. Retrieved August 24, 2020, from http://www.aunsec.org/pdf/8.2.6CODOC.pdf

Kato, R., \& Reeder, K. (2015). Research Forum: “I Didn't Know Who Is Canadian”: The Shift in Student Expectations During the Initial Stages of a Study Abroad Program. JALT Journal 37.1 JALT Journal, 37(1), 43. https://doi.org/10.37546/JALTJJ37.1-3

King, R., \& Sondhi, G. (2018). International student migration: a comparison of UK and Indian students' motivations for studying abroad. Globalisation, Societies and Education, 16(2), 176-191. https://doi.org/10.1080/14767724.2017.1405244

Koleski, K., Blivas A., \& United States-China Economic and Security Review Commission (2018). China's Engagement with Latin America and the Caribbean. Washington D.C.: U.S.-China Economic and Security Review Commission. Retrieved August 26, 2020, from https://www.uscc.gov/sites/default/files/Research/China's\%20Engagement\%20with\%20Latin\%20America\%20a nd\%20the\%20Caribbean_.pdf

Kondakci, Y. (2011). Student mobility reviewed: Attraction and satisfaction of international students in Turkey. Higher Education, 62(5), 573-592. Retrieved July 19, 2020, from www.jstor.org/stable/41477888. https://doi.org/10.1007/s10734-011-9406-2

Kumar, S. (2015). India's trade in higher education. Higher Education, 70(3), 441-467. Retrieved July 6, 2020, from www.jstor.org/stable/43648881. https://doi.org/10.1007/s10734-014-9846-6

Liang-Hsuan, C. (2006). Attracting east asian students to canadian graduate schools. The Canadian Journal of Higher Education, 36(2), 77-105. https://doi.org/10.1007/s10734-006-9022-8

Lopez-Leyva, S., \& Rhoades, G. (2016). Country Competitiveness Relationship with Higher Education Indicators. Journal of technology management \& innovation, $11(4), \quad 47-55$. https://doi.org/10.4067/S0718-27242016000400007

Lu, C., \& Han, W. (2010). Why Don't They Participate? A Self-Study of Chinese Graduate Students' Classroom:Involvement in North America. Brock Education Journal, 20(1). https://doi.org/10.26522/brocked.v20i1.147

Marope, P. T. M., Wells, P. J., \& Hazelkorn, E. (Eds.). (2013). Rankings and accountability in higher education: Uses and misuses. Paris: UNESCO.

Moher, D., Liberati, A., Tetzlaff, J., Altman, D. G., \& The PRISMA Group (2009). Preferred Reporting Items for Systematic Reviews and Meta-Analyses: The PRISMA Statement. PLoS Med 6(7): e1000097. https://doi.org/10.1371/journal.pmed.1000097

Montt, M., \& Rehner, J. (2020). Del Galeón de Manila a la IED: Rutas de intercambio entre China y América Latina. In Asia América Latina, 5(8), 8-31. https://doi:10.33177/8.3

Morley, L., Leyton, D., \& Hada, Y. (2019). The affective economy of internationalisation: Migrant academics in and out of Japanese higher education. Policy Reviews in Higher Education, 3(1), 51-74. https://doi.org/10.1080/23322969.2018.1564353

Organisation for Economic Co-operation and Development. (2019) What is the profile of internationally mobile students? Education at a Glance 2019: OECD Indicators. OECD iLibrary. Retrieved August 14, 2020, from https://www.oecd-ilibrary.org/sites/17d19cd9en/index.html?itemId=\%2Fcontent\%2Fcomponent\%2F17d19cd9en

Perna, L. W., Orosz, K., Jumakulov, Z., Kishkentayeva, M., \& Ashirbekov, A. (2014). Understanding the programmatic and contextual forces that influence participation in a government-sponsored international student-mobility program. Higher Education, 69(2), 173-188. https://doi.org/10.1007/s10734-014-9767-4

Pontificia Universidad Católica de Chile. (2020). Informe de Análisis: Datos de Iniciativas Históricas de la Movilidad Estudiantil en Pregrado. Unpublished raw data.

Ramírez Bonilla, J. J. (2016). Iniciativas institucionales latinoamericanas para generar conocimiento sobre Asia. Universidades, (69), 9-21. [fecha de Consulta 13 de Agosto de 2020]. ISSN: 0041-8935. Recuperado de: https://www.redalyc.org/articulo.oa?id=37348528003 
Redden, E. (2020). COVID-19 disrupts international student exchange in both directions. Retrieved August 14, 2020, from

https://www.insidehighered.com/news/2020/03/20/covid-19-disrupts-international-student-exchange-both-direct ions

Rhein, D., \& Jones, W. (2020). The impact of ethnicity on the sociocultural adjustment of international students in Thai higher education. Educational Research for Policy and Practice. https://doi.org/10.1007/s10671-020-09263-9

Ruiz-Corbella, M., \& Álvarez-González, B. (2014). Virtual Mobility as an Inclusion Strategy in Higher Education: Research on Distance Education Master Degrees in Europe, Latin America and Asia. Research in Comparative and International Education, 9(2), 165-180. https://doi.org/10.2304/rcie.2014.9.2.165

Santander Trade. (2020). Chilean foreign trade in figures. Retrieved August 14, 2020, from https://santandertrade.com/en/portal/analyse-markets/chile/foreign-trade-in-figures

Segrera, F. L., Brock, C., \& Sobrinho, J. D. (2009). Higher education in Latin America and the Caribbean 2008. Caracas: UNESCO, IESALC.

Snodin, N. (2019). Mobility experiences of international students in Thai higher education. International Journal of Educational Management, 33(7), 1653-1669. https://doi.org/10.1108/IJEM-07-2018-0206

Spate, O. H. (1979). The Spanish Lake. London: Croom Helm. https://doi.org/10.26530/oapen_459544

Teichler, Ulrich. (2017) Internationalisation Trends in Higher Education and the Changing Role of International Student Mobility. Journal of international Mobility, vol.1, No 5 https://doi.org/10.3917/jim.005.0179

The Asian Development Bank Institute, Organisation for Economic Co-operation, \& Development and International Labour Organization. (2014). Labor Migration, Skills \& Student Mobility in Asia. Retrieved August 14, 2020, from https://www.oecd.org/migration/Labour-migration-skills-student-mobility-in-Asia.pdf

Tobenkin, D. (2020, January 02). Is It Time for a U.S. International Education Strategy? Retrieved August 14, 2020, from https://www.nafsa.org/ie-magazine/2020/1/2/it-time-us-international-education-strategy

Trilokekar, R. D., \& Kukar, P. (2011). Disorienting experiences during study abroad: Reflections of pre-service teacher candidates. Teaching and Teacher Education, 27(7), 1141-1150. https://doi.org/10.1016/j.tate.2011.06.002

U.S. News \& World Report (2020). The Best Universities in Latin America, Ranked. Retrieved August 14, 2020, from https://www.usnews.com/education/best-global-universities/latin-america

UNESCO Institute for Statistics (2014). Higher Education in Asia: Expanding Out, Expanding Up. The rise of graduate education and university research. Retrieved August 14, 2020, from Higher Education in Asia: Expanding Out, Expanding Up The rise of graduate education and university research

UNESCO Institute for Statistics. (2020). UIS Statistics. Retrieved August 14, 2020, from http://data.uis.unesco.org/

UNESCO International Institute for Higher Education in Latin America and the Caribbean. (2019). UNESCO IESALC REVEALS THAT ONLY 38\% OF MOBILITY FROM LATIN AMERICA AND THE CARIBBEAN IS TO THE SAME REGION. Retrieved August $\quad$ 14, 2020, from https://www.iesalc.unesco.org/en/2019/09/25/unesco-iesalc-reveals-that-only-38-of-mobility-from-latin-america -and-the-caribbean-is-to-the-same-region/

Vasilopoulos, G. (2019). The Practicality and Relevance of Peace in an EFL Teacher Training Program: Applications and Implications. Critical Inquiry in Language Studies, 16(1), 10-29. https://doi.org/10.1080/15427587.2018.1520599

Walton-Roberts, M. (2015). Femininity, mobility and family fears: Indian international student migration and transnational parental control. Journal of Cultural Geography, 32(1), 68-82. https://doi.org/10.1080/08873631.2014.1000561

Wilson Center. (2014). REACHING ACROSS THE PACIFIC: Latin America and Asia in the New Century (C. J. Arnson, J. Heine, \& C. Zaino, Eds.). Retrieved August 14, 2020, from https://www.wilsoncenter.org/sites/default/files/media/documents/publication/Reaching_Across_the_Pacific_20 14_WWC.pdf

Winston, S. (2016, April 27). The Intertwining History of Asia and Latin America. Retrieved August 14, 2020, from https://www.panoramas.pitt.edu/art-and-culture/intertwining-history-asia-and-latin-america 
World Bank. (2020). COVID-19 Coronavirus Response. Retrieved August 14, 2020, from http://pubdocs.worldbank.org/en/506241590701178057/EAP-TE-and-COVID-19-FINAL-26May20.pdf

World Integrated Trade Solution. (2020a). Brazil exports, imports and trade balance By Country and Region. $\begin{array}{llll}\text { Retrieved } \quad \text { August } & 24, & \text { 2020, }\end{array}$ https://wits.worldbank.org/CountryProfile/en/Country/BRA/Year/2018/TradeFlow/EXPIMP

World Integrated Trade Solution. (2020b). Mexico Trade. Retrieved August 24, 2020, from https://wits.worldbank.org/countrysnapshot/en/MEX

Zhang, C. (2020). Who bypasses the Great Firewall in China? First Monday, 25(4). https://doi.org/10.5210/fm.v25i4.10256

Xiong, W., Mok, K., Ke, G., \& Cheung, J. (2020). Impact of COVID-19 Pandemic on International Higher Education and Student Mobility: Student Perspectives from Mainland China and Hong Kong. Centre for Global Higher Education, Department of Education, University of Oxford. Retrieved December 26, 2020, from https://www.researchcghe.org/perch/resources/publications/wp54to-publish.pdf

Zwart, J. (2013). Study abroad choices of chinese students: Factors, influences and motivations. Quarterly Journal of Chinese Studies, 2(2), 68-90.

\section{Copyrights}

Copyright for this article is retained by the author(s), with first publication rights granted to the journal.

This is an open-access article distributed under the terms and conditions of the Creative Commons Attribution license (http://creativecommons.org/licenses/by/4.0/). 